\title{
DisTRIBUCIÓN Y VARIABILIDAD MORFOLÓgICA DE POBLACIONES DE SOLANUM COMMERSONII (SOLANACEAE) EN LA REGIÓN PAMPEANA DE LA Argentina
}

\author{
AGUSTÍN PRIETO, VERÓNICA N. ISPIZÚA y ANDREA M. CLAUSEN¹
}

\begin{abstract}
Summary: Distribution and morphological variability in populations of Solanum commersonii (Solanaceae) in the Pampas region of Argentina. Solanum commersonii is a wild tuber bearing species, widely distributed in the Distrito Pampeano Austral and Oriental of Argentina. It is found growing in different habitats: on coastal dunes and in Paspalum quadrifarium tussocks distributed both in the lowland as well as on the hillsides. In order to compare the populations from the different sites, 17 populations of $S$. commersonii, one of $S$. malmeanum and one of $S$. chacoense, the last two species included as outgroups, were studied. Morphological and reproductive characters were registered in 6 to 10 plants in each population studied and the data were analyzed by means of an analysis of variance, components and coordinates. A minimum spanning tree was calculated to visualize the groups formed. The results obtained with the morphological analysis revealed that the intraspecific variability detected in the populations was not associated with the particular habitat where the species grows.
\end{abstract}

Key words: Distribution, intraespecific variability, lowland areas and hills, sandy dunes, Solanum commersonii.

Resumen: Solanum commersonii es una especie tuberosa silvestre de papa ampliamente distribuida en el Distrito Pampeano Austral y Oriental de la Argentina, creciendo en ambientes muy diversos: en la costa sobre médanos e integrando pastizales relictuales de paja colorada tanto en campos bajos con limitantes edáficas como en las laderas de la sierras. Con el objetivo de comparar las poblaciones provenientes de diferentes sitios y ambientes se analizaron 17 poblaciones de Solanum commersonni, una entrada de Solanum malmeanum y una de Solanum chacoense, estas dos últimas utilizadas como grupos taxonómicamente relacionados. Se registraron 41 caracteres morfológicos vegetativos y reproductivos, en seis a diez plantas por población. Los datos fueron analizados mediante un análisis de varianza, de coordenadas y componentes principales. Se calculó un árbol de mínima distancia para visualizar los posibles agrupamientos. Los resultados del análisis morfológico detectaron que la variabilidad intraespecifica en las poblaciones estudiadas de $S$. commersonii no está asociada a los diferentes ambientes donde crece la especie.

Palabras clave: Ambientes serranos, campo bajo, distribución, dunas costeras, Solanum commersonii, variabilidad intraespecífica.

\section{INTRODUCCIÓN}

Las especies silvestres de papa, pertenecientes al género Solanum L. sect. Petota Dumort., poseen una amplia distribución en nuestro país, desde el nivel del mar hasta los $4.300 \mathrm{msnm}$, con la mayor diversidad de especies en el noroeste argentino (Clausen et al., 2005). En esta sección, se detectan

${ }^{1}$ Facultad de Ciencias Agrarias, UNMdP. C. C. 276,7620 Balcarce, Argentina. ispizua.veronica@inta.gob.ar distintos niveles de ploidía (desde diploides a hexaploides) y son frecuentes los fenómenos de plasticidad fenotípica, introgresión e hibridación interespecifica (Hawkes \& Hjerting 1969; Spooner et al., 2004). Introgresión e hibridación interespecifica son consideradas una de las causas frecuentes de las dificultades taxonómicas encontradas en este grupo (Spooner et al., 2007). El número de especies descriptas en la sección Petota se ha reducido paulatinamente como resultado de distintas revisiones, desde 232 especies (Hawkes, 1990) hasta 110 según Spooner (2009). 
Solanum commersonii Dunal es una especie de amplia distribución en la Argentina, Uruguay y Brasil (Clausen et al., 2013); la provincia de Buenos Aires constituye el límite austral de su distribución, y se la encuentra en el Distrito Pampeano Oriental y Austral integrando diversos ambientes y comunidades. Crece en una amplia diversidad de hábitats ya que se la encuentra en terrenos bajos, húmedos, sobre las laderas de las sierras, integrando pajonales relictuales así como en suelos arenosos, alterados, en los bordes de arroyos, al costado de los caminos, campos cultivados, zonas boscosas de Araucaria angustiflolia (Bertol.) Kuntze y de palmeras, Butia yatay (Mart.) Becc., entre rocas marítimas y dunas costeras, desde el nivel del mar hasta los $400 \mathrm{msnm}$ (Correll, 1962; Hawkes \& Hjerting, 1969; Hawkes, 1990; Laterra et al., 2003; Ispizúa et al., 2004, Clausen et al., 2013). Es una especie que posee tolerancia a estreses bióticos y abióticos (Palta et al., 1981; Seppänen et al., 2000; Siri et al., 2009; González et al., 2013; Pino et al., 2013), de gran importancia para su utilización en el mejoramiento genético de la papa (Solanum tuberosum L.).

En la provincia de Buenos Aires, en las sierras del partido de Balcarce y General Pueyrredón, Cabrera (1965) cita a $S$. commersonii como una especie que integra los matorrales de curro (Colletia paradoxa (Spreng.) Escal.). También en el partido de Balcarce, Millán y Grondona, (citado por Hawkes \& Hjerting, 1969) en colecciones llevadas a cabo en distintos años, la encuentran entre arbustos de Colletia, en las sierras alrededor de Balcarce junto a gramíneas, hierbas y vegetación arbustiva. S. commersonii crece asociada a pajonales de Paspalum quadrifarium Lam. tanto en los campos bajos de la Pampa Deprimida como en los ecosistemas serranos (Alonso et al., 1995; Laterra, 2003; Ispizúa et al., 2004).

Solanum commersonii fue denominada por Dunal, en honor a Philibert Commerson quien la coleccionó en mayo de 1767, en Montevideo, Uruguay. Esta especie fue probablemente la primera papa silvestre recolectada así como la primera en ser denominada y descripta como resultado de una expedición científica (Hawkes \& Hjerting, 1969). Hawkes \& Hjerting (1969) y Hawkes (1990), describieron dos subespecies: commersonii y malmeanun, destacando la existencia de considerable variabilidad infraespecifica en ambas subespecies; Mentz \& Oliveira (2004) y Matesevach \& Barboza (2005) aceptaron este mismo tratamiento. Correll (1962) considera a estas subespecies como formas, diferenciando a la fo. malmeanum de la fo. commersonii por la presencia de algunos folíolos peciolados y de dos o más folíolos intermedios entre cada par de folíolos laterales. Como resultado de recientes revisiones en colecciones de ambas subespecies, actualmente se ha propuesto considerar a la subespecie malmeanum como una especie distinta de $S$. commersonii por las características morfológicas distintivas entre ellas (Clausen et al., 2013).

Solanum commersonii ha sido descripta como una especie generalmente de bajo porte, de 15 a 30 $\mathrm{cm}$ de altura, semi-arrosetada a erecta. Posee hojas imparipinnadas de 6,5 a $14,5 \mathrm{~cm}$ de largo x 3,3 $-7,8 \mathrm{~cm}$ de ancho, de color verde, con dos a cinco pares de folíolos laterales, sésiles o cortamente peciolulados, que disminuyen gradualmente su tamaño hacia la base de la hoja. El folíolo terminal se caracteriza por ser de mayor tamaño que los laterales, pudiendo ser sésil o peciolulado, de forma ovada a ampliamente elíptica, de ápice generalmente obtuso y de base cuneada. La inflorescencia está compuesta por 3 a 12 flores, la corola es de forma estrellada, de color violeta, a veces blanco con tintes violáceos. Los frutos son de color verde, de forma ovoidea a cónica (Correll, 1962; Hawkes \& Hjerting, 1969; Prieto, 2011; Clausen et al., 2013). Se reproduce en forma sexual por semillas y asexual por medio de tubérculos de $2-5 \mathrm{~cm}$ de diámetro; la época de floración se extiende desde febrero a junio en la Provincia de Buenos Aires. Se han detectado citotipos diploides $(2 n=2 x=24)$ $\mathrm{y}$ triploides $(2 \mathrm{n}=3 \mathrm{x}=36)$ en esta especie (Hawkes, 1990); según Tarn \& Hawkes (1986) los citotipos triploides serían de origen autotriploide.

El estudio de la variabilidad morfológica asociada a patrones de distribución geográfica, provee información útil tanto para formular estrategias de conservación in situ y ex situ como para la utilización de $S$. commersonii en el mejoramiento genético del cultivo de la papa. En el Distrito Pampeano Austral y Oriental se coleccionaron poblaciones de S. commersonii de diferentes ambientes (laderas de sierras, campos bajos de la Pampa Deprimida y médanos costeros) en los partidos de La Costa, Gral. Pueyrredón, Balcarce, Lobería, Tandil, Rauch y Olavarría conservadas ex 


\section{A. Prieto et al. - Distribución y variabilidad morfológica de S. commersonii}

situ en el Banco de Germoplasma de la Estación Experimental Agropecuaria Balcarce, INTA (Ispizúa et al., 2004; Tillería \& Zomuz, 2013). El presente trabajo tiene como objetivos comparar mediante caracteres morfológicos las poblaciones de $S$. commersonii de los diferentes sitios de colecta y ambientes, determinar los caracteres morfológicos que contribuyan a la diferenciación de las poblaciones estudiadas y determinar si hay variantes morfológicas asociados a los distintos ambientes.

\section{Materiales y Métodos}

Para el análisis de poblaciones provenientes de distintos ambientes, se estudiaron 17 poblaciones de Solanum commersonni, una de Solanum malmeanum y de Solanum chacoense, estas dos últimas especies utilizadas como grupos taxonómicamente relacionados (Fig. 1). Las semillas fueron provistas por el Banco de Germoplasma (EEA Balcarce, INTA).

Ejemplares de herbario de todos los materiales

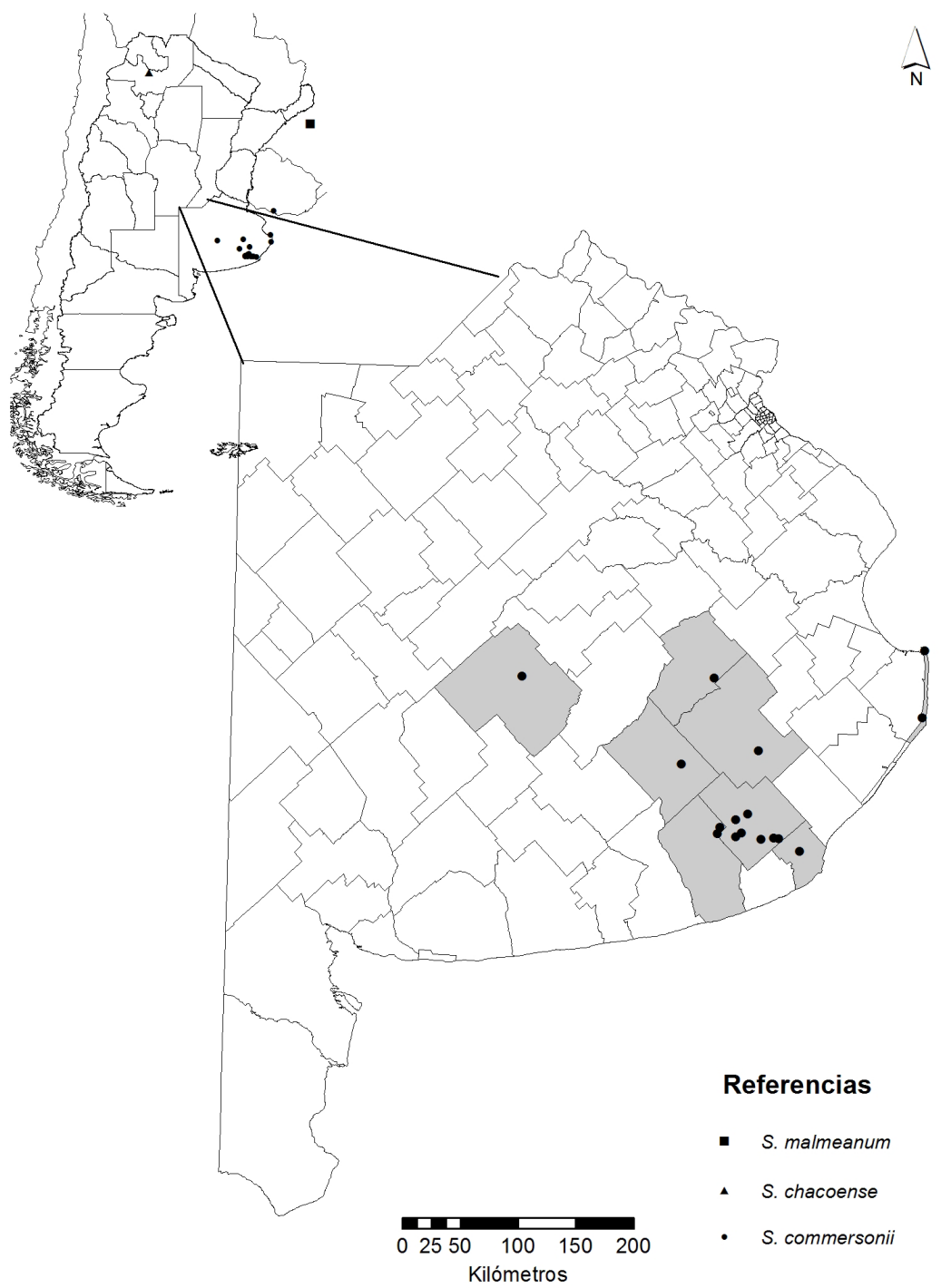

Fig. 1: Mapa con la distribución de las especies estudiadas. 
incluidos en este trabajo, se encuentran depositados en el Herbario BAL (Clausen \& Castaño, 1998). Los especímenes estudiados con sus datos de colecta y número de plantas estudiadas, se citan a continuación:

Solanum chacoense Bitter. ARGENTINA. Prov. Salta, Dpto. Capital, Quebrada de San Lorenzo, $24^{\circ} 43^{\prime} \mathrm{S}-65^{\circ} 29^{\prime} \mathrm{O}, 1343 \mathrm{msnm}$, Clausen \& Stabile 1743 (10).

Solanum commersonii Dunal. ARGENTINA. Prov. Buenos Aires, Pdo. Ayacucho, Paraje San Ignacio, $37^{\circ} 20^{\prime} \mathrm{S}-58^{\circ} 25^{\prime} \mathrm{O}, 96 \mathrm{msnm}$, Clausen \& Ispizúa 1148 (8). Pdo. de la Costa, San Clemente del Tuyú, 36 $16^{\circ} \mathrm{S}-56^{\circ} 44^{\prime} \mathrm{O}, 9$ msnm, Ispizúa, Stabile \& Alonso 11 (9). Pinamar, $36^{\circ} 50^{\prime} \mathrm{S}-56^{\circ}$ 42'O, 8 msnm, Ispizúa, Stabile \& Alonso 12 (9). Pdo. Balcarce, Sierra Chata, $37^{\circ} 53^{\prime} \mathrm{S}-58^{\circ}$ $22^{\prime} \mathrm{O}, 160 \mathrm{msnm}$, Clausen \& Ispizúa 1114 (7). Estancia Cinco Cerros, $37^{\circ} 42^{\prime} \mathrm{S}-58^{\circ} 16^{\prime} \mathrm{O}$, 170 msnm, Clausen \& Ispizúa 1121 (9). Sierra La Vigilancia, $37^{\circ} 52^{\prime} \mathrm{S}-58^{\circ} 00^{\prime} \mathrm{O}, 137 \mathrm{msnm}$, Clausen \& Ispizúa 1123 (9). Cerro Amarante, $37^{\circ} 50^{\prime} \mathrm{S}-58^{\circ} 22^{\prime} \mathrm{O}, 203 \mathrm{msnm}$, Clausen \& Ispizúa 1139 (8). Sierra La Brava, 37 52' $\mathrm{S}-57^{\circ}$ 59'O, 106 msnm, Clausen \& Ispizúa 1135 (8). Sierra El Volcán, $37^{\circ} 51^{\prime} \mathrm{S}-58^{\circ} 08^{\prime} \mathrm{O}, 210 \mathrm{msnm}$, Clausen \& Ispizúa 1129 (10). Cerro El Moro, $37^{\circ}$ $44^{\prime} \mathrm{S}-58^{\circ} 25^{\prime} \mathrm{O}, 205 \mathrm{msnm}$, Clausen \& Ispizúa 1150 (7). Pdo. General Pueyrredón, Sierra de los Padres, $37^{\circ} 95^{\prime} \mathrm{S}-57^{\circ} 76^{\prime} \mathrm{O}, 123 \mathrm{msnm}$,
Clausen \& Alonso 1098 (6). Pdo. Lobería, Cerro

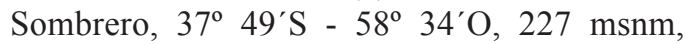
Clausen \& Ispizúa 1140 (10). Sierra Larga, $37^{\circ}$ 49'S - 58 36' O, 247 msnm, Clausen \& Ispizúa 1141 (8). Pdo. Olavarría, Cerro La China, $36^{\circ}$ 49'S - 60 33'O, 255 msnm, Clausen \& Ispizúa 1154 (9). Pdo. Rauch, Estación Langheyú, $36^{\circ}$ $40^{\prime} \mathrm{S}-58^{\circ} 44^{\prime} \mathrm{O}, 42 \mathrm{msnm}$, Clausen \& Ispizúa 1159 (10). Pdo. Tandil, Cerro Redondo, $37^{\circ} 21^{\prime} \mathrm{S}$ - 58 59'O, 247 msnm, Clausen \& Ispizúa 1142 (10). URUGUAY. Departamento Canelones, Río Santa Lucía, $34^{\circ} 35^{\prime} \mathrm{S}-56^{\circ} 29^{\prime} \mathrm{O}, 74 \mathrm{msnm}$, Hawkes 702 (6).

Solanum malmeanum Bitter. BRASIL. Estado Rio Grande Do Sul: Municipio Ijui, Ijui, 28 23' S $53^{\circ} 55^{\prime} \mathrm{O}, 330$ msnm, Brücher 19 (7).

Se efectuó la siembra y el cultivo de los materiales en una jaula antiáfidos bajo condiciones de óptima humedad. Los registros de los caracteres morfológicos estudiados se realizaron en antesis; las mediciones de los caracteres vegetativos se realizaron sobre la tercera hoja verdadera desde la base de la planta y los caracteres florales sobre la primera inflorescencia.

Se registraron 41 caracteres morfológicos, de los cuales 18 eran vegetativos y 23 reproductivos. El conjunto de los caracteres comprendió 11 cualitativos y 30 cuantitativos. En la Tabla 1 se incluyen los caracteres mencionados para cada OTU con sus respectivos estados.

\section{Tabla 1. Caracteres vegetativos y reproductivos y sus estados registrados en los materiales estudiados.}

1. Hábito de crecimiento (1: erecto, 2: postrado); 2. Altura (cm); 3. Pilosidad del tallo (1: muy piloso, 2: escasamente piloso, 3: glabro); 4. Color del tallo (1: verde [100\% tallo verde]; 2: Verde con púrpura en inserción de la hoja, 3: verde y púrpura [presentes ambos colores en un 50\%], 4: mayormente púrpura, 5: totalmente púrpura); 5. Largo de hoja (cm); 6. Ancho de hoja $(\mathrm{cm}) ; 7$. Ancho del primer par de folíolos primarios $(\mathrm{cm}) ; 8$. Largo del folíolo terminal $(\mathrm{cm}) ; 9$. Ancho del folíolo terminal $(\mathrm{cm}) ; 10$. Longitud del peciólulo $(\mathrm{cm})$; 11. Forma base folíolo terminal (1: cuneada, 2: truncada a levemente cuneada, 3: truncada, 4: asimétrica, 5: truncada a levemente cordada, 6: cordada); 12. Largo del primer folíolo lateral (cm); 13 Ancho del primer folíolo lateral $(\mathrm{cm}) ; 14$. Largo del segundo folíolo lateral (cm); 15. Ancho del segundo folíolo lateral $(\mathrm{cm}) ; 16$. Número de pares de folíolos laterales; 17 . Número de folíolos intermedios; 18. Número de folíolos secundarios; 19. Largo del pedúnculo $(\mathrm{cm}) ; 20$ : Longitud del raquis de la inflorescencia (cm); 21. Número de raquis de la inflorescencia; 22. Número de flores/inflorescencia; 23. Longitud del pedicelo (cm); 24. Longitud desde la inserción del cáliz a la articulación del pedicelo $(\mathrm{cm}) ; 25$. Longitud del cáliz $(\mathrm{cm}) ; 26$. Longitud del acumen del cáliz (cm); 27. Longitud del lóbulo del cáliz (cm); 28. Radio de la corola (cm); 29. Longitud del centro de la corola a la unión del lóbulo $(\mathrm{cm}) ; 30$. Ancho del lóbulo de la corola $(\mathrm{cm}) ; 31$. Longitud desde la base de la corola hasta el ápice del lóbulo (cm); 32. Color del tejido interpetalar adaxial ; 33. Color del tejido interpetalar abaxial; 34. Color de los rayos de la corola cara abaxial; 35. Color de los rayos de la corola cara adaxial; 36. Color del acumen de la corola adaxial; 37 . Color del acumen de la corola lado abaxial; 38. Largo antera $(\mathrm{cm})$; 39. Largo estilo $(\mathrm{cm})$; 40. Forma del estilo (1: capitado, 2: clavado, 3: bilobado); 41. Exserción del estilo (cm). 
Para cada una de las variables cuantitativas analizadas se calcularon los valores promedio, el desvío estándar y el valor máximo y mínimo. Se efectúo un análisis de la varianza y las diferencias de medias se analizaron a través del test LSD de Fisher $(\mathrm{P}<0,05)$. El procesamiento de los datos se realizó con el programa InfoStat (2010).

Se utilizaron técnicas de taxonomía numérica mediante las cuales es posible calcular la afinidad entre unidades taxonómicas en base al estado de sus caracteres (Crisci \& López Armengol, 1983). Para registrar el valor de cada uno de los caracteres se obtuvo el valor promedio del total de las plantas medidas por población para los caracteres cuantitativos y para los cualitativos se utilizó la moda. Las variables cualitativas y cuantitativas fueron analizadas en conjunto mediante el análisis de coordenadas principales (ACoordP) empleando el coeficiente de Gower (1971). Se obtuvo una matriz de similaridad que fue transformada mediante doble centrado, y a partir de la misma se calcularon y graficaron los autovectores. Se calculó un árbol de mínima distancia y se superpuso sobre la proyección de las OTU's en el análisis mencionado anteriormente. Las variables cuantitativas fueron consideradas empleando un análisis de componentes principales (ACP) que permitió identificar las variables más discriminatorias. Para este análisis, se calculó una matriz de correlación, se obtuvieron los autovalores y se efectuó la proyección de los dos primeros componentes. Para decidir sobre la bondad de los resultados obtenidos por la aplicación de ambas técnicas utilizadas en este estudio se calculó el coeficiente de correlación cofenético (Sokal \& Rohlf, 1962). El procesamiento de los datos se realizó con el programa InfoStat (2010).

Para la nomenclatura botánica se utilizó la versión digital de la Flora Argentina - Plantas Vasculares de la Republica Argentina, 2012, www. floraargentina.edu.ar

\section{Resultados}

El análisis de varianza realizado para los caracteres vegetativos y reproductivos cuantitativos reveló diferencias significativas para 27 de las 29 variables registradas (Tabla 2). Los caracteres, longitud del acumen del cáliz y el número de raquis de la inflorescencia no mostraron diferencias significativas. Con excepción de la longitud del peciólulo, número de flores por inflorescencia y radio de la corola, los restantes caracteres fueron significativos al $0,01 \%$. El carácter número de folíolos secundarios no presento variación por lo tanto no fue considerado en los análisis efectuados.

El Análisis de Componentes Principales (ACP), considerando 29 variables cuantitativas, reveló que los tres primeros valores propios explicaron un $34,4 \%, 19,6 \%$ y $9,9 \%$ respectivamente de la variabilidad total (Fig. 2). El coeficiente de correlación cofenético de este análisis fue alto, $\mathrm{r}=0,96$. Para el primer componente los caracteres que más contribuyeron con su mayor valor absoluto, en orden decreciente fueron: ancho del segundo folíolo lateral, ancho del primer par de folíolos primarios, ancho del primer folíolo lateral, ancho de hoja, largo del primer folíolo lateral, largo de hoja, largo del segundo folíolo lateral (Tabla 3). El primer componente permitió separar las poblaciones de S. commersonii que registraron mayores valores en los caracteres asociados al tamaño de la hoja. Se destaca que CII 1139 es la población con el menor tamaño de hoja, mientras que ClS 1154 presenta los mayores valores para estos caracteres, evidenciándose la variabilidad detectada en $S$. commersonii en cuanto a su morfología foliar.

En el segundo componente los caracteres que más contribuyeron fueron, en orden decreciente: longitud desde la base de la corola hasta el ápice del lóbulo, número de folíolos intermedios, longitud del pedicelo, exserción del estilo y altura (Tabla 3). Caracteres como altura, número de intermedios y exserción determinaron que las poblaciones que registraron mayores valores en los mismos se encontraran en el cuadrante inferior del gráfico, mientras que las poblaciones que se encontraron en el cuadrante superior son las que presentaron mayores valores para los caracteres longitud desde la base hasta el ápice del lóbulo de la corola y longitud del pedicelo.

En el análisis de coordenadas principales (ACoordP) no se incluyeron los caracteres hábito de crecimiento, forma de la base del folíolo terminal y forma del estilo por no presentar variación en las poblaciones analizadas en este trabajo. Al aplicar dicho análisis sobre la matriz básica de $17 \times 38$, sobre la matriz de similitud, empleando 
Tabla 2. Caracteres cuantitativos para cada una de las poblaciones analizadas (expresados como media, \pm desvío estándar, valor mínimo y máximo). Análisis de la varianza y comparación de medias ( $\mathrm{P}<0,05$, LSD de comparaciones múltiples).

\begin{tabular}{|c|c|c|c|c|c|}
\hline Variable & Media & CV\% & $\begin{array}{l}\text { Valor } \\
\text { Mínimo }\end{array}$ & $\begin{array}{l}\text { Valor } \\
\text { Máximo }\end{array}$ & $\begin{array}{c}\text { Nivel de } \\
\text { significancia } \\
\text { LSD }^{\#}\end{array}$ \\
\hline Altura & $22,77 \pm 17,47$ & 76,74 & 10 & 115 & ** \\
\hline Largo de hoja & $10,55 \pm 3,16$ & 29,95 & 4,50 & 18,30 & ** \\
\hline Ancho de hoja & $5,11 \pm 1,92$ & 37,54 & 2,00 & 10,50 & ** \\
\hline Ancho primer par de folíolos primarios & $4,99 \pm 1,83$ & 36,69 & 1,50 & 10,50 & ** \\
\hline Largo folíolo terminal & $4,57 \pm 1,40$ & 30,57 & 1,10 & 8,60 & ** \\
\hline Ancho folíolo terminal & $2,46 \pm 0,73$ & 29,74 & 0,50 & 4,60 & ** \\
\hline Longitud peciólulo & $0,43 \pm 0,18$ & 41,83 & 0 & 1,20 & * \\
\hline Largo primer folíolo lateral & $2,65 \pm 0,90$ & 33,93 & 0,50 & 5,50 & ** \\
\hline Ancho primer folíolo lateral & $1,29 \pm 0,45$ & 35,21 & 0,40 & 2,90 & ** \\
\hline Largo segundo folíolo lateral & $2,17 \pm 1,03$ & 47,70 & 0 & 4,7 & ** \\
\hline Ancho segundo folíolo lateral & $1,14 \pm 0,51$ & 44,63 & 0 & 2,60 & ** \\
\hline Número pares folíolos laterales & $3,40 \pm 0,99$ & 29,23 & 1 & 6 & ** \\
\hline Número de folíolos intermedios & $0,79 \pm 1,24$ & 156,87 & 0 & 6 & ** \\
\hline Largo del pedúnculo & $3,37 \pm 2,23$ & 66,09 & 0,10 & 11 & ** \\
\hline Longitud del raquis de inflorescencia & $0,78 \pm 0,83$ & 107,41 & 0 & 5,30 & $* *$ \\
\hline Número de raquis de la inflorescencia & $1,75 \pm 0,80$ & 45,94 & 0 & 5 & ns \\
\hline Número de flores/inflorescencia & $8,53 \pm 4,19$ & 49,11 & 2,00 & 22 & * \\
\hline Longitud del pedicelo & $1,86 \pm 0,89$ & 48,19 & 0,40 & 5,50 & ** \\
\hline $\begin{array}{l}\text { Longitud desde inserción del cáliz } \\
\text { a articulación del pedicelo }\end{array}$ & $0,92 \pm 0,77$ & 84,33 & 0,10 & 4 & ** \\
\hline Longitud del cáliz & $0,49 \pm 0,12$ & 25,21 & 0,30 & 1,10 & ** \\
\hline Longitud acumen del cáliz & $0,12 \pm 0,04$ & 32,70 & 0,10 & 0,30 & ns \\
\hline Longitud lóbulo del cáliz & $0,29 \pm 0,09$ & 30,92 & 0,10 & 1 & ** \\
\hline Radio de corola & $1,59 \pm 0,29$ & 18,48 & 0,80 & 2,30 & * \\
\hline Longitud del centro de corola a unión del lóbulo & $0,40 \pm 0,18$ & 46,10 & 0,10 & 1,20 & ** \\
\hline Ancho del lóbulo de la corola & $0,61 \pm 0,16$ & 25,50 & 0,30 & 1,20 & ** \\
\hline Longitud desde base de corola hasta ápice del lóbulo & $1,19 \pm 0,27$ & 22,56 & 0,40 & 2,10 & ** \\
\hline Largo antera & $0,53 \pm 0,08$ & 15,85 & 0,30 & 0,80 & ** \\
\hline Largo estilo & $0,96 \pm 0,12$ & 12,20 & 0,40 & 1,20 & ** \\
\hline Exserción del estilo & $0,29 \pm 0,11$ & 39,26 & 0,10 & 0,70 & $\star \star$ \\
\hline
\end{tabular}

\# diferencias significativas entre poblaciones (LSD). Niveles de significancia $p<0,01\left(^{* *}\right) ; p<0,05\left(^{*}\right)$; ns= no significativo 


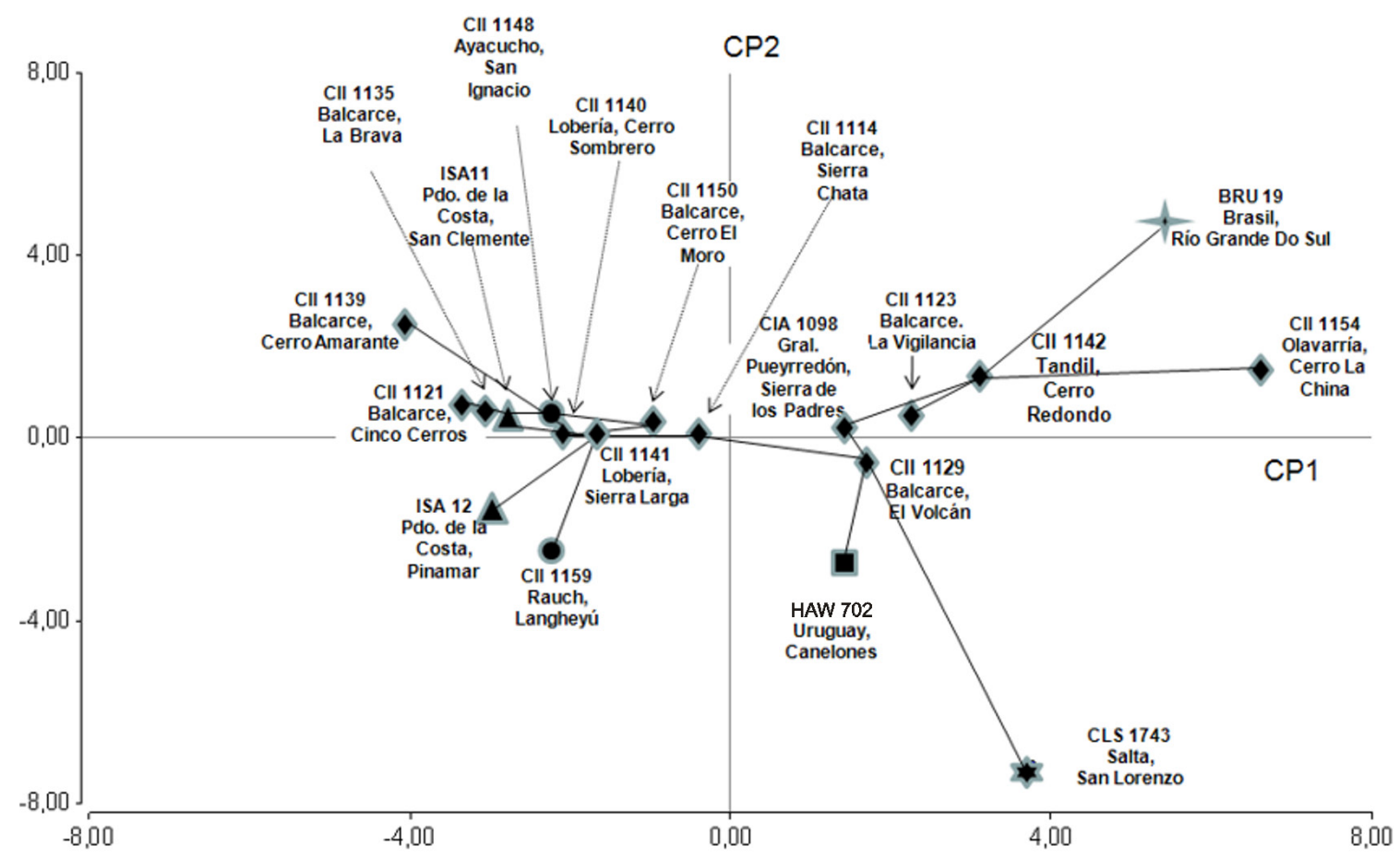

Fig. 2: ACP. Representación de las poblaciones estudiadas de Solanum commersonii (cmm) sobre los dos primeros componentes. $\triangle \mathrm{cmm}$ ambiente sierra; $\triangle \mathrm{cmm}$ médanos; $\mathrm{cmm}$ campo bajo; $\mathbf{\square} \mathrm{cmm}$ Uruguay; +S. malmeanum; $\boldsymbol{\star}$ S. chacoense.

el coeficiente de Gower, se encontró que las tres primeras coordenadas explicaron un porcentaje de la variabilidad igual a 22,16 y $11 \%$ respectivamente. En la Figura 3 se presenta la ubicación de los OTU's en función de las coordenadas 1 y 2 , a la que se le superpuso un árbol de mínima distancia. El grado de ajuste estimado a través del coeficiente de correlación cofenético $(\mathrm{r}=0,96)$, reveló una muy buena representación de la matriz de similitud por el ACoordP.

$\mathrm{Al}$ superponer el árbol de mínima distancia sobre el ACoorP se observa la conformación de cuatro grupos ubicados en cada uno de los cuadrantes del gráfico dentro de los cuales se agrupan poblaciones con características similares entre sí (Fig. 3). El grupo 1 y 2, ubicados en los cuadrantes superior e inferior del gráfico, están integrados por poblaciones coleccionadas en los cerros de Tandil y Olavarría, y en tres sierras ubicadas al sudeste de la ciudad de Balcarce creciendo en pajonales de Paspalum quadrifarium (Fig. 4). Estas poblaciones se caracterizan por presentar a nivel vegetativo, hojas de mayor tamaño (mayor longitud de la hoja, del f líolo terminal y lateral, mayor ancho de la hoja, del folíolo lateral y los folíolos laterales). Dentro del grupo 2, la población ClS 1154 proveniente del cerro La China (Olavarría) es la que registró los valores mayores para los caracteres mencionados anteriormente. En la parte inferior del gráfico las poblaciones que conforman los grupos 1 y 4, presentan como característica común, el color blanco de los acúmenes de la corola diferenciándose por este carácter de las poblaciones que integran los grupos 2 y 3 cuyos acúmenes son de color violáceo. En el cuadrante superior izquierdo se ubica el grupo 3 integrado por cinco poblaciones. Tres agrupadas en el sector derecho del cuadrante: CII 1159, CII 1150, CII 1114 coleccionadas en pastizales de "paja colorada", en campo natural y ambiente serrano respectivamente, y dos dispuestas en el centro del cuadrante: ISA 12, ISA 11 coleccionadas en el Partido de la Costa sobre médanos. Dentro de este grupo, estas dos últimas poblaciones, registraron el menor valor promedio en la altura de planta, largo y ancho de hoja, ancho del folíolo terminal y en el 
Bol. Soc. Argent. Bot. 51 (1) 2016

Tabla 3. Autovectores y autovalores de los tres componentes principales para las variables morfológicas analizadas en el ACP.

\begin{tabular}{|c|c|c|c|}
\hline \multirow{2}{*}{ Carácter } & \multicolumn{3}{|c|}{ Autovectores } \\
\hline & C1 & $\mathrm{C} 2$ & C3 \\
\hline Altura & 0,12 & 0,30 & 0,18 \\
\hline Largo de hoja & 0,29 & 0,04 & $-0,15$ \\
\hline Ancho de hoja & 0,30 & $-0,14$ & $-0,02$ \\
\hline Ancho del primer par de folíolos primarios & 0,30 & $-0,12$ & $-0,03$ \\
\hline Largo del folíolo terminal & 0,23 & $-0,04$ & 0,01 \\
\hline Ancho del folíolo terminal & 0,02 & 0,15 & 0,29 \\
\hline Longitud del peciólulo & 0,14 & 0,13 & 0,13 \\
\hline Largo del primer folíolo lateral & 0,29 & $-0,14$ & $-0,01$ \\
\hline Ancho del primer folíolo lateral & 0,30 & $-0,04$ & $-0,07$ \\
\hline Largo del segundo folíolo lateral & 0,28 & $-0,16$ & 0,03 \\
\hline Ancho del segundo folíolo lateral & 0,30 & $-0,09$ & $-0,02$ \\
\hline Número de pares de folíolos laterales & 0,22 & $-0,12$ & 0,06 \\
\hline Número de folíolos intermedios & 0,10 & $-0,34$ & 0,07 \\
\hline Largo del pedúnculo & 0,17 & 0,15 & $-0,22$ \\
\hline Longitud del raquis de la inflorescencia & 0,19 & 0,07 & 0,18 \\
\hline Número de raquis de la inflorescencia & 0,10 & 0,13 & 0,16 \\
\hline Número de flores/inflorescencia & 0,03 & $-0,08$ & 0,18 \\
\hline Longitud del pedicelo & 0,15 & 0,32 & $-0,10$ \\
\hline Longitud desde la inserción del cáliz a la articulación del pedicelo & 0,19 & 0,25 & $-0,10$ \\
\hline Longitud del cáliz & 0,18 & 0,21 & 0,25 \\
\hline Longitud del acumen del cáliz & 0,17 & 0,01 & 0,02 \\
\hline Longitud del lóbulo del cáliz & 0,13 & 0,25 & 0,11 \\
\hline Radio de la corola & 0,04 & 0,19 & 0,41 \\
\hline Longitud del centro de la corola a la unión del lóbulo & 0,03 & $-0,23$ & 0,25 \\
\hline Ancho del lóbulo de la corola & 0,07 & 0,10 & 0,06 \\
\hline Longitud desde la base de la corola hasta el ápice del lóbulo & 0,02 & 0,35 & 0,20 \\
\hline Largo antera & $-0,11$ & $-0,02$ & 0,27 \\
\hline Largo estilo & $-0,04$ & $-0,06$ & 0,47 \\
\hline Exserción del estilo & $-0,11$ & $-0,31$ & 0,16 \\
\hline Autovalores & 9,98 & 5,67 & 2,89 \\
\hline Proporción de la variabilidad explicada & 34,42 & 19,67 & 9,9 \\
\hline Porcentaje acumulado & 34,42 & 54,02 & 63,98 \\
\hline
\end{tabular}

Referencias: Celdas sombreadas oscuras indican coeficientes de mayor peso en cada autovector. 


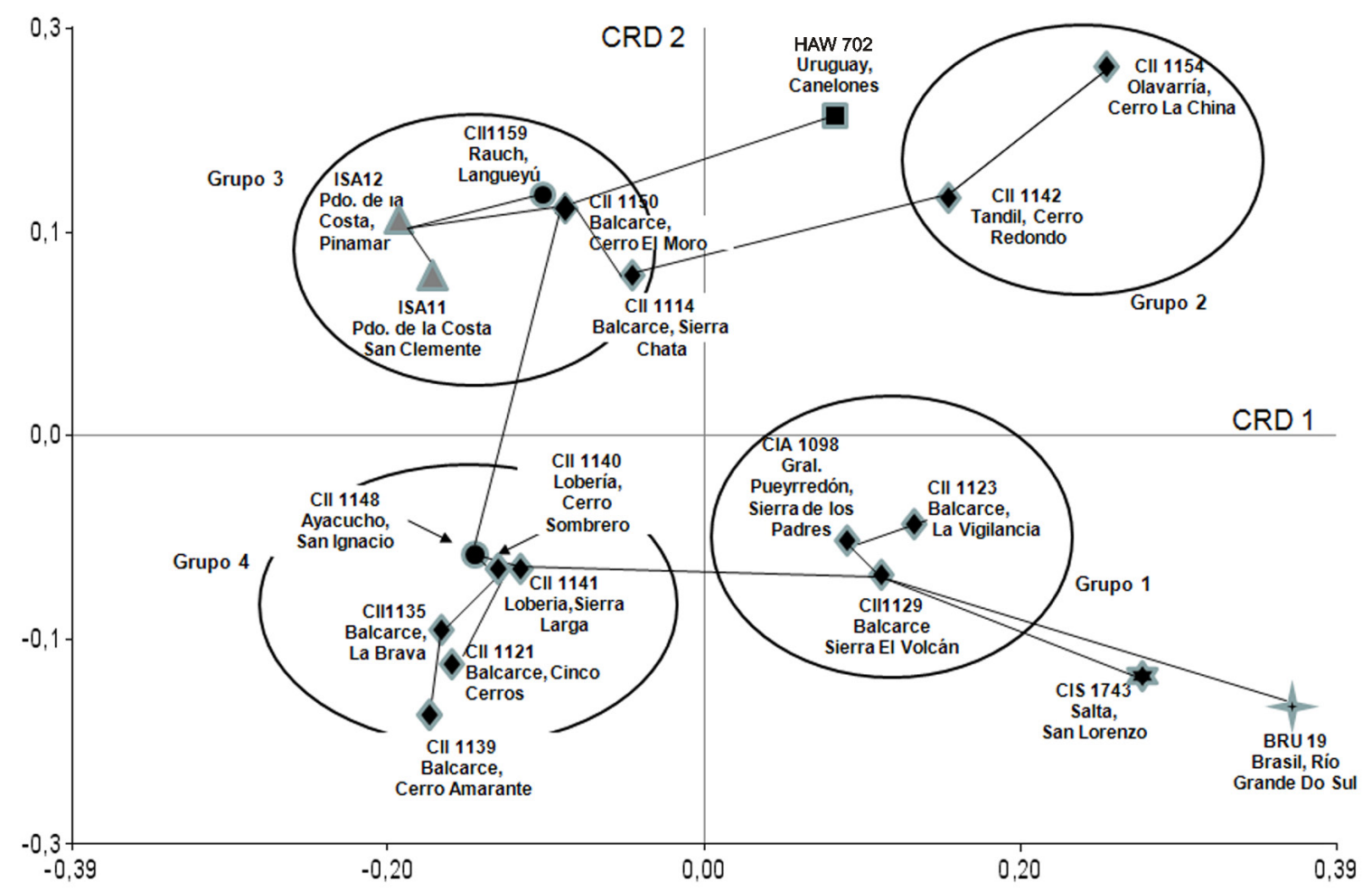

Fig. 3: ACoordP. Representación de las poblaciones estudiadas de Solanum commersonii (cmm) sobre las dos primeras coordenadas. $\mathrm{cmm}$ ambiente sierra; $\triangle \mathrm{cmm}$ médanos; $\mathrm{cmm}$ campo bajo; $\mathbf{G m m}$ Uruguay; + S. malmeanum; S. chacoense.

número de flores por inflorescencia. En el cuadrante inferior izquierdo se observa el grupo 4 integrado por seis poblaciones coleccionadas en ambiente serrano y campo bajo natural. La población ClI 1139 se caracteriza por presentar menor ancho y longitud de los folíolos laterales, mayor ancho del folíolo terminal y mayor radio de la corola. La población proveniente del litoral uruguayo, Hawkes 702, ubicada aproximadamente a $19 \mathrm{~km}$ de la costa, se ubica en el cuadrante superior derecho cercano a materiales más distantes de la costa argentina.

Las dos poblaciones, ClS 1743 y Bru 19, pertenecientes a $S$. chacoense y a S. malmeanum respectivamente, se ubicaron en los cuadrantes inferiores derechos, distantes del grupo perteneciente a $S$. commersonii y unidos por líneas separadas en el árbol de mínima distancia, y la misma configuración se observó en el ACP. A diferencia de S. commersonii, estas especies poseen flores blancas y plantas de mayor altura.

\section{Discusión}

Solanum commersonii es una especie de amplia distribución en el Distrito Pampeano Austral y Oriental, caracterizándose por colonizar ambientes muy diversos tales como regiones serranas, costeras y campos bajos con limitantes edáficas. Presenta una gran persistencia ya que estas áreas se encuentran frecuentemente sometidas a pastoreo intensivo y a quemas (Laterra et al., 2003) y subsiste como consecuencia de su sistema de reproducción tanto vegetativo como reproductivo. En relación a los disturbios a los cuales es sometida esta especie, se ha observado que las plantas que crecen en una ladera de la Sierra La Vigilancia en un pajonal sin pastoreo pueden alcanzar más de un metro de altura creciendo dentro de matas de Paspalum (Clausen com. pers.), mientras que en un pajonal, con una alta presión de pastoreo, esta especie se la encuentra en la parte basal de las matas con un porte bajo y arrosetado. 


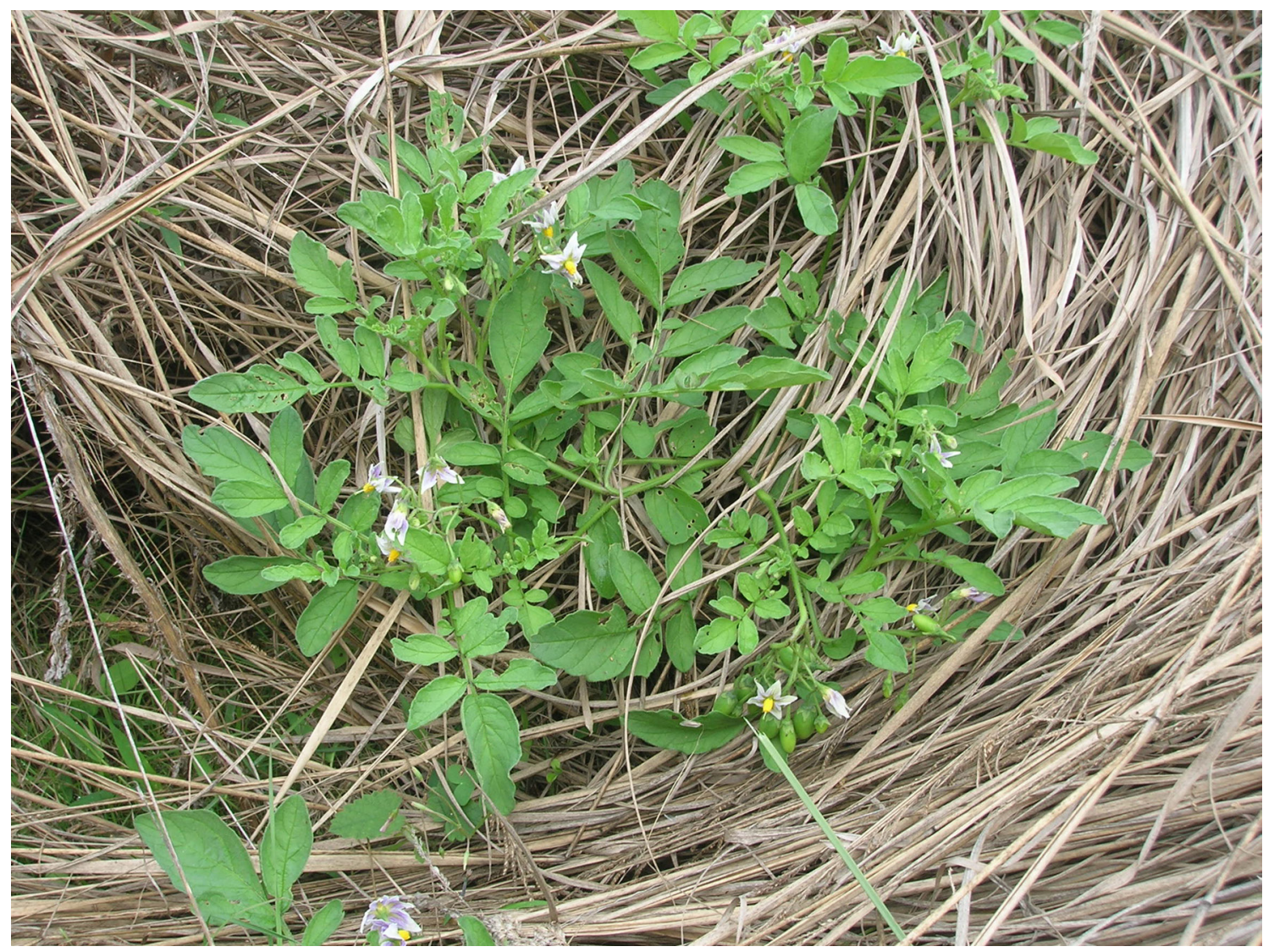

Fig. 4: Solanum commersonii creciendo entre matas de Paspalum quadrifarium.

En la Pampa Deprimida de la Provincia de Buenos Aires, S. commersonii crece entre matas de Paspalum quadrifarium Lam. ("paja colorada") y/o P. exaltatum Presl. ("paja de embarrar"). Este "paspaletum", constituye un tipo de pastizal que se caracteriza por la abundancia de estas especies, junto a otras especies acompañantes tales como Althernanthera philoxeroides (Mart.) Griseb., Lotus tenuis Waldst. \& Kit. ex Willd., Dipsacus fullonum L., Phyla canescens (Kunth) Greene, Verbena intermedia Gillies \& Hook. ex Hook. Phil., Physalis viscosa L., Solanum chenopodioides Lam., Eryngium eburneum Decne, Bromus auleticus Trin., Cirsium vulgare Airy-Shaw. En los pajonales de Paspalum, la superficie del suelo libre del área basal de las matas, se encuentra generalmente cubierta por material vegetal muerto ("broza"), lo que genera condiciones aptas para el establecimiento de algunas especies, entre ellas $S$. commersonii.

El sistema de Tandilia constituye un cordón serrano discontinuo que se extiende a lo largo de $350 \mathrm{~km}$ desde las proximidades de la ciudad de Olavarría hasta Mar del Plata. Desde el punto de vista fitogeográfico, las sierras de este sistema se encuentran dentro del Distrito Pampeano Austral de la Provincia Pampeana, del dominio Chaqueño (Cabrera \& Willink, 1980). En las laderas de las sierras predominan en el estrato herbáceo la "paja de embarrar" (Paspalum exaltatum) y la "paja colorada" (Paspalum quadrifarium) y en las laderas más secas se desarrollan pajonales de "cortadera" (Cortaderia selloana (Schult. \& Schult.f.) Asch. \& Graebn. y de "carda" (Eryngium horridum Malme, E. regnellii Malme, E. serra Cham. \& Schltdl.). $\mathrm{Al}$ ascender, aparecen matorrales de "carquejas" y "chilcas" (Baccharis articulata (Lam.) Pers., Baccharis coridifolia DC., Baccharis tandilensis 
Speg.) así como también otras especies tales como Senecio pulcher Hook. \& Am. pulcher, Gomphrena perennis L., Stevia satureiifolia (Lam.) Sch. Bip., Chrysolaena flexuosa Sims, Gyptis tanacetifolia (Gillies ex Hook. \& Arn.) D.J.N. Hind \& Flann y Poa iridifolia Hauman. Característicos matorrales de "curro" (Colletia paradoxa) se desarrollan desde la base hasta la cima. La presencia de $S$. commersonii se registra en el estrato herbáceo dominado por "paja colorada", "paja de embarrar" y "cortaderas" así como entre matorrales de "carquejas", "chilcas" y "curro" entre los 106-330 msnm. En algunas de las zonas de la región serrana en la que aparece $S$. commersonii, se observa la invasión de una especie exótica leñosa, Rubus ulmifolius Schott ("zarzamora").

En la región costera, $S$. commersonii se encuentra creciendo en los albardones de conchillas y arenisca de la ribera platense, a 8-9 msnm, a veces a escasos metros del mar; también crece en zonas con dunas costeras fijas o semifijas que se caracterizan por la presencia de una cobertura vegetal integrada por pastizales. Las poblaciones de esta papa silvestre frecuentemente se encuentran protegidas por "cortaderas". Entre las especies acompañantes se destacan Juncus acutus L.(Parl.) Snogerup A. St.-Hil., Hydrocotile bonariensis Lam., Solidago chilensis Meyen, Ambrosia tenuifolia Spreng., Cenchrus echinatus L., Imperata cilindrica (L.) P. Beauv., Adesmia incana Vogel, Bowlesia incana Ruiz \& Pav., Medicago lupulina L., Tessaria absinthioides (Hook \& Arn.) DC., Spartina densiflora Brongn., Gamochaeta stachydifolia (Lam.) Cabrera, Solidago chilensis Meyen.

Los resultados obtenidos en este trabajo detectaron variabilidad morfológica entre las poblaciones estudiadas de $S$. commersonii; los caracteres cuantitativos vegetativos contribuyeron en mayor medida a la diferenciación detectada en las poblaciones estudiadas y de éstos, los relacionados con la hoja fueron los más discriminantes.

No se encontró una asociación entre las poblaciones procedentes de distintos ambientes (campo bajo, sierra y médanos) y las variantes morfológicas encontradas en $S$. commersonii. Esto se evidencia en la dispersión en los cuatro cuadrantes en el AcoordP de poblaciones provenientes de ambientes serranos las que a su vez presentan similitudes con poblaciones de otros ambientes (campo bajo y médanos) en dos de los cuatro cuadrantes. Las poblaciones de $S$. commersonii, a pesar de integrar la vegetación de una sierra, un bajo o un médano, se desarrollan en un micro-ambiente similar, entre la broza y debajo de las matas de "paja colorada" en las sierras y en los campos bajos, o de las plantas de "cortadera" en los médanos, con buena disponibilidad de humedad. Estas condiciones presentes en los tres ambientes, le proporcionan protección y un microambiente adecuado para su crecimiento pero no se expresan variantes morfológicas específicas o asociadas a cada ambiente. Por otra parte, encontramos una correlación entre la distancia geográfica y las variantes morfológicas en algunos casos, como por ejemplo las dos poblaciones provenientes de los ambientes serranos más distantes de la costa atlántica (Tandil y Olavarría), son morfológicamente similares entre sí; lo mismo ocurre con las poblaciones provenientes de las sierras del partido de Lobería y las dos poblaciones del ambiente de médanos. En S. chacoense, especie tuberosa silvestre de amplia distribución en nuestro país, Juned et al., (1988), encontraron variantes morfológicas en la altura de planta, longitud del peciólulo, posición de la articulación del pedicelo y longitud del acumen del cáliz, correlacionadas con gradientes altitudinales; posteriormente Miller $\&$ Spooner (1996) detectaron en base a caracteres morfológicos y moleculares (RAPDs), que las poblaciones de $S$. chacoense provenientes de ambientes ubicados a baja altura (menos de 1500 m) se diferenciaban con dificultad de aquellas provenientes de áreas de mayor altura en el noroeste argentino. Ambos trabajos incluyeron ambientes muy diversos, con gradientes altitudinales mayores que los encontrados para $S$. commersonii.

Pianzzola et al., (2005) detectaron variabilidad a nivel bioquímico y molecular en $S$. commersonii proveniente de Uruguay, y mediante perfiles genéticos obtenidos de marcadores RAPDs pudieron diferenciar todas las poblaciones del sur de Uruguay estudiadas, aún aquellas de un mismo sitio de colecta; esta diversidad no se encontró asociada a un patrón de distribución geográfica. Resultados similares fueron encontrados por Galván et al., (2007) en esta misma especie a través del análisis de la presencia de lectinas, glicoalcaloides y resistencia a Ralstonia solanacearum, detectando variación intraespecífica que no se encontraba asociada a un patrón de distribución geográfica, 
en materiales coleccionados desde las Sierras de Lavalleja y Treinta y Tres hasta la costa del Río de la Plata, a pocos metros del mar. Siri et al., (2009), trabajando con materiales de $S$. commersonii del Uruguay, detectaron altos niveles de polimorfismo para tres distintos marcadores moleculares, pero no encontraron correlación entre resistencia a Ralstonia solanacearum, variación genética y distribución geográfica.

En las especies tuberosas del género Solanum, ocurren frecuentemente fenómenos de plasticidad fenotípica, introgresión e hibridación interespecífica (Hawkes \& Hjerting 1969; Spooner et al., 2004). En la naturaleza, las especies silvestres de papa están aisladas por barreras externas espaciales y ecológicas (Hawkes \& Hjerting, 1969) así como por barreras internas prezigóticas (Grun \& Aubertin, 1966) y postzigóticas (Johnston et al., 1980). Se han formulado numerosas hipótesis de hibridación en las especies tuberosas silvestres (Spooner \& van den Berg 1992) y una de ellas en $S$. commersonii. La hipótesis de híbridos naturales de $S$. chacoense $\times S$. commersonii fue formulado por Hawkes \& Hjerting (1969) al detectar variabilidad en poblaciones de $S$. commersonii, pero la misma no se pudo sustentar ya que existen mecanismos de aislamiento postzigótico, en este caso en particular el aborto del endosperma, que imposibilitaría la hibridación entre ambas especies (Jonhston et al., 1980). Además, como resultado del relevamiento realizado, no hemos encontrado a estas dos especies creciendo en forma simpátrica en la provincia de Buenos Aires, por lo que se puede excluir como causa de la variabilidad encontrada en $S$. commersonii, la hibridación interespecífica.

Conclusiones. Este trabajo ha aportado información sobre la variabilidad presente en las poblaciones de $S$. commersonii provenientes de la región pampeana, así como los caracteres morfológicos que contribuyen a explicar dicha variabilidad. Nuestro estudio no nos ha permitido detectar asociación entre ambientes y las variantes morfológicas encontradas. Futuros estudios incluirán la utilización de marcadores moleculares a fin de obtener información sobre la diversidad genética existente en el área de estudio y proveer pautas para su conservación in situ en ambientes serranos del Distrito Pampeano Austral y en el Distrito Pampeano Oriental.

\section{Agradecimientos}

Este trabajo fue realizado en el marco de los Proyectos: UNMdP (AGR 448/14). Inventario, colecta y evaluación de recursos fitogenéticos de valor agronómico y ornamental. 2014-2015 y PE AERG 231221. INTA. Conservación ex situ y valoración de las colecciones de germoplasma de la Red de Recursos Genéticos Vegetales del INTA.

\section{Bibliografia}

ALONSO, S., P. LATERRA \& F. GARITA. 1995. Paspalum exaltatum Presl en los pajonales de paja colorada del sudeste bonaerense. Rev. Arg. Prod. Animal 15: 97-99.

CABRERA, A.L. 1965. Flora de la provincia de Buenos Aires. Col. Cient. Inst. Nac. Tecnol. Agropec. Tomo 4, Parte 5.

CABRERA, A.L. \& A. WILLINK. 1980. Biogeografia de América latina. OEA. Programa de desarrollo científico y tecnológico. Serie de Biología. Monografía $\mathrm{N}^{\mathrm{o}} 13$.

CLAUSEN, A.M. \& M. C. CASTAÑO. 1998. Catálogo del material del herbario BAL Solanum L. sect. Petota. EEA Balcarce, INTA. Inédito.

CLAUSEN, A.M., M. COLAVITA, I. BUTZONITCH. \& A. V. CARRANZA, A. V. 2005. A potato collecting expedition in the province of Jujuy, Argentina and disease indexing of virus and fungus pathogens in Andean cultivars. Genet. Resour. Crop Ev. 52: 10991109.

CLAUSEN, A. M., I. E. PERALTA \& D. M. SPOONER. 2013. Grupo VIII. Potato. In: A. M. Anton \& F. O. Zuloaga (eds.). Flora Argentina (Flora Vascular de la República Argentina).Vol 13: 264-289.

CORRELL, D. S. 1962. The potato and its wild relatives, section Tuberarium of the genus Solanum. Renner, Texas Research Foundation.

CRISCI, J. V. \& M. F. LOPEZ ARMEGOL. 1983. Introducción a la teoría y práctica de la Taxonomía numérica. OEA, Washington D. C.

GALVÁN, G., L. FRANCO FRAGUAS, L. QUIRICI, C. SANTOS, E. SILVERA, M. I. SIRI, P. VILLANUEVA, L. RAUDIVINICHE, M. GONZALEZ, D. TORRES, A. CASTILLO, M. DALLA RIZZA, F. VILARÓ, V. GEPP, F. FERREIRA \& M. J. PIANZZOLA. 2007. Solanum commersonii: una especie con gran potencial para el mejoramiento genético de papa por resistencia a Ralstonia solanacearum. In: Clausen, A. M., F. Condon \& A. Berretta (eds). Avances de investigación en recursos genéticos en el Cono Sur II, pp. 87-101. PROCISUR, IICA, Uruguay. 


\section{A. Prieto et al. - Distribución y variabilidad morfológica de S. commersonii}

GONZÁLEZ, M., G. GALVÁN, M. I., SIRI, A. BORGES \& F. VILARÓ. 2013. Resistencia a la marchitez bacteriana de la papa en Solanum commersonii Dun. Agrociencia 17: 45-54. GOWER, J.C. 1971. A general coefficient of similarity and some of its properties. Biometrics 27:857-874.

GRUN, P. \& M. AUBERTIN. 1966. The inheritance and expression of unilateral incompatibility in Solanum. Heredity 21: 131-138.

HAWKES, J.G. \& J.P. HJERTING. 1969. The potatoes of Argentina, Brazil, Paraguay and Uruguay. A biosistematic study. Oxford University Press, Oxford.

HAWKES, J.G. 1990. The Potato. Evolution, Biodiversity and Genetic Resources. Belhaven Press, London.

INFOSTAT. 2010. InfoStat versión 2010. Grupo InfoStat, FCA; Universidad Nacional de Córdoba, Argentina.

ISPIZÚA, V.N., A.M. CLAUSEN \& M. COLAVITA. 2004. Colecta y conservación de Solanum commersonii Dun. en pastizales relictuales del distrito pampeano Austral. Actas II Reunión Binacional de Ecología. XXI Reunión Argentina de Ecología. XI Reunión de la Sociedad de Ecología de Chile. Mendoza, p. 260.

JOHNSTON, S. A., T. P. M. DEN NIJS, S. J. PELOQUIN, \& R. E. HANNEMAN, JR. 1980. The significance of genic balance to endosperm development in interspecific crosses. Theor. Appl. Genet. 57: 5-9.

JUNED, S.A., M. T. JACKSON \& J. P. CATTY. 1988. Diversity in the wild potato species Solanum chacoense Bitt. Euphytica 37: 149-156.

LATERRA, P. 2003. Desde el Paspaletum: bases ecológicas para el manejo de pajonales húmedos con quemas prescriptas. Cap. 9, pp 93-107. In: Kunst C.R., S. Bravo, J. L. Panigatti (eds.) 2003. Fuego en los Ecosistemas Argentinos. Ediciones INTA. Santiago del Estero.

LATERRA, P., O. R. VIGNOLIO, M. P. LINARES, A. GIAQUINTA \& N. MACEIRA. 2003. Cumulative effects of fire on tussock pampa grassland. $J$. Vegetation Sci. 14: 43-54.

MATESEVACH, M. \& G. BARBOZA. 2005. Solanaceae, parte 13. Tribu 1. Solaneae, parte 2. Solanum subgen. Potatoe, sect. Petota. Flora Fanerogámica Argentina 87: 3-37.

MENTZ, L. A. \& P. L. OLIVEIRA. 2004. Solanum (Solanaceae) na região sul do Brazil. Pesquisas Botanica 54: 1-327.

MILLER, J. T. \& D. M. SPOONER. 1996. Introgression of Solanum chacoense (Solanum sect. Petota): upland populations reexamined. Syst. Bot. 21: 461-475.

PALTA, J.P., H. H. CHEN, \& P.H. LI. 1981. Relationship between heat and frost resistance of tuber-bearing Solanum species: effect of cold acclimation on heat resistance. Bot. Gaz. 142: 311-315.

PIANZZOLA, M. J., L. ZARANTONELLI, G. GONZALEZ, L. FRANCO-FRAGUAS \& A.
VAZQUEZ. 2005. Genetic, phytochemical and biochemical analysis as tools for diversity evaluation of wild accessions of Solanum commersonii. Biochem. System. Ecol. 33:67-78.

PINO, M.T., A. ÁVILA, A. MOLINA, Z. JEKNIC \& T.H.H. CHEN. 2013. Enhanced in vitro drought tolerance of Solanum tuberosum and Solanum commersonii plants overexpressing the ScCBF1 gene. Cien. Inv. Agr. 40:171-184.

PRIETO, A. 2011. Caracterización morfológica de poblaciones de Solanum commersonii Dunal del distrito pampeano austral de la Argentina. Tesis Ing. Agr. FCA UNMdP. Inédito.

SEPPÄNEN, M. M., T. CARDI, M. B. HYÖKKI \& E. PEHU. 2000. Characterization and expression of cold-induced glutathione S-transferase in freezing tolerant Solanum commersonii, sensitive S. tuberosum and their interspecific somatic hybrids. Plant Sci.153: 125-133.

SIRI, M. I., G. A. GALVAN, L. QUIRICI, E. SIBERA, P. VILLANUEVA, F. FERRERIRA, L. FRANCO \& M. J. PIANZZOLA. 2009. Molecular marker diversity and bacterial wilt resistance in wild Solanum commersonii accessions from Uruguay. Euphytica 165: 371-382.

SOKAL, R.R. \& F. J. ROHLF. 1962. The comparison of dendograms by objective methods. Taxon 11: 33-44.

SPOONER, D. M. \& R. G. VAN DEN BERG. 1992. Species limits and hypotheses of hybridization of Solanum berthaultii Hawkes and S. tarijense Hawkes: morphological data. Taxon 41: 685-700.

SPOONER, D. M., R. G. VAN DEN BERG, G.J. BRYAN, A. DEL RIO. 2004. Species concepts and reduction of species in wild and cultivated potatoes (Solanum section Petota). Acta Hort. 619:63-75.

SPOONER, D. M., D. FAJARDO \& G.J. BRYAN. 2007. Species limits of Solanum berthaultii Hawkes and $S$. tarijense Hawkes and the implications for species boundaries in Solanum sect. Petota. Taxon 56: $987-$ 999.

SPOONER, D. M. 2009. DNA barcoding will frequently fail in complicated groups: an example in wild potatoes. Am. J. Bot. 96: 1177-1189.

TARN, T. R. \& J. G. Hawkes. 1986. Cytogenetic studies and the occurrence of triploidy in the wild potato species Solanum commersonii Dun. Euphytica 35: 293-302.

TILLERÍA, J. \& J. ZAMUZ, 2013. DBGERMOWeb -Sistema Curatorial para la Documentación de Colecciones Vegetales de Germoplasma [Software], INTA, Argentina.

Recibido el 17 de julio de 2015, aceptado el 12 de noviembre de 2015 . 
